\title{
К ПОНЯТИЮ «ЭСХАТОЛОГИЧЕСКАЯ ИДЕЙНАЯ ГРУППА»
}

\section{TO THE CONCEPT OF "ESCHATOLOGICAL IDEOLOGICAL GROUP"}

\section{Blokhin}

Summary: The article discusses the phenomenon of an eschatological ideological group in society, and describes the various ways in which such groups exist in society, analyzes possible ways of interaction of ideological groups with society and their impact on each individual person. The appearance and use of the term "ideological group" is due to the fact that it accurately delineates the boundaries and functions of uniting people on ideological grounds. Particular attention is paid to eschatological ideological groups. In the research process, a method of system analysis and typologization was used.

The stages of development of ideological groups from emergence to completion of its existence are considered. In the period of the formation of an ideological group from the moment the idea appears to the complete cessation of any kind of activity, the group goes through a multi-stage and complex development path. Using the method of typologizing the stages of development of an ideological group, it was possible to distinguish ideological groups according to their individual characteristics and external characteristics.

To establish the causes and factors (external and internal) of the emergence of the ideological group, a system analysis was used. The emergence of an ideological group in society is due to the fact that it goes beyond the framework of tradition in its ideological space, and an idea different from the generally accepted one is opposed to public opinion. The activities of an ideological group can affect society, and society can have an impact on ideological groups.

Keywords: eschatology, idea, eschatological idea, eschatological ideological group, ideological group, typology of ideological groups, analysis of ideological groups.
$\mathrm{B}$ настоящее время в научном сообществе рассматривается идея эсхатологии. Она рассматривается как основная составляющая религиозного верования; как часть мифов и также в качестве самостоятельной темы для мифологии. Однако в качестве основной идеи и формирующего механизма для создания идейного сообщества эсхатология рассматривается редко. В данном исследовании с точки зрения системного социальнофилософского анализа рассматривается возможный ход событий, при которых формируется эсхатологическая идейная группа. Этот способ проведения анализа даёт новую возможность смоделировать весь ход событий от возникновения до прекращения существования объекта исследования - эсхатологической идейной группы. Проведение системного анализа даёт возможность исследования способа существования эсхатологической идеи в обществе. Анализируемые сообщества необходи-
Блохин Дмитрий Германович Аспирант, Астраханский государственный университет yamissioner@gmail.com

Аннотация: В статье рассматривается феномен эсхатологической идейной группы в обществе, и описываются различные способы существования подобных групп в обществе, анализируются возможные способы взаимодействия идейных групп с социумом и их влияние на каждого отдельно взятого человека. Появление и использование термина «идейная группа» обусловлено тем, что он точно очерчивает границы и функции объединения людей по идейным признакам. Особое внимание уделено эсхатологическим идейным группам. В процессе исследования использовались метод системного анализа и типологизации.

Рассмотрены этапы развития идейных групп от возникновения до завершения своего существования. В период становления идейной группы от момента появления идеи до полного прекращения какого-либо рода деятельности, группа проходит многоступенчатый и сложный путь развития. Использование метода типологизации этапов развития идейной группы позволило провести различия идейных групп по своим индивидуальным особенностям и внешним характеристикам.

Для установления причин и факторов (внешних и внутренних) появления идейной группы, был использован системный анализ. Возникновение идейной группы в обществе обусловлено тем, что она выходит за рамки традиции в своём идейном пространстве, а отличная от общепринятых идея противопоставляется общественному мнению. Деятельность идейной группы может повлиять на общество, а общество может оказывать влияние на идейные группы.

Ключевые слова: эсхатология, идея, эсхатологическая идея, эсхатологическая идейная группа, идейная группа, типологизация идейных групп, анализ идейных групп.

мы в качестве способа существования эсхатологических идей в обществе в целом. Результатом анализа может стать прогнозирование деятельности и осуществление контроля над деятельностью части общества, находящегося под влиянием какой-либо конкретной эсхатологической идеи или системы идей.

Идея, идейность в рамках данного исследования понимается так, как это сформулировал Лосев: «Если предмет прямо приравнивается идее, то «идея» ничего иного не может обозначать, как собранность, цельность, конкретно-видимую смысловую организованность многого в некое непосредственно данное единство, а это мы как раз и называем интегральностью».[4, с. 108] Следовательно, идея функциональна и является частью мыслительного процесса. «Социальное бытие заново воплощает логику, символику и мифологию и меняет их 
отвлечённые контуры до полной неузнаваемости. Поэтому платоновская идея должна предстать перед нами как социальное явление».[4, с. 499] «Четвёртый - диалектический - тип понимания платоновской Идеи есть трансцендентальное понимание, т.е. толкование идеи как логического принципа, как метода, как априорного условия возможности опыта».[4, с. 488]

Здесь под общей идеей понимается тема, которая есть результат мыслительной деятельности на основе предпосылки, затем уверенности, как продукта мыслительной деятельности и убеждённости в чём-либо на основе личных или групповых рассуждений. Далее идея может передаваться другим людям, которые принимают её на веру, возможно и без предоставления какихлибо доказательств. Так возникает и распространяется идея как движущая сила идейной группы в обществе. Как пишет Х. Ортега-и-Гассет: «И здесь мы обнаруживаем иной слой идей. Но как отличаются эти идеи от тех, что приходят нам в голову или нами усваиваются! Эти фундаментальные «идеи», которые я называю «верованиями»». [5, с. 405]

Благодаря вере и рождающейся из нее убежденности, идея, существующая сначала как результат мыслительной деятельности одного отдельно взятого человека или группы людей, может стать социальным феноменом. Идея может послужить также началом продуцируемых из нее других идей. Например, эсхатологическая идейная группа, известная под названием «Миллеритское движение». [1; 6, с. 147 - 159] Началась деятельность группы с ошибочного толкования текстов Священного Писания Библии бродячим проповедником христианства и одновременно масоном У. Миллером. После распространения идеи Второго Пришествия Христа на Землю, которое было запланировано Миллером на весну 1844 года образовалась идейная группа последователей, которые ожидали конкретно этой даты. После наступления разочарования из этой группы взяла своё начало религиозная организация «Адвентисты седьмого дня», существующая по настоящее время. Это яркий пример эсхатологической идейной группы, спонтанно возникшей в обществе.

В статье проанализировано и описано возникновение, и дальнейшее формирование подобных сообществ, имеющих своей основной идеей предпосылки к эсхатологическим событиям, поэтому следует конкретизировать вводимое понятие «эсхатологическая идейная группа». В рамках данного исследования, события, связанные с концом света или прекращением истории называются эсхатологическими, и все они понимаются в качестве составных частей эсхатологической идеи. Отсюда: эсхатологическая идейная группа - это группа единомышленников, имеющих своей основной целью нахождение способа спасения от конца света или обре- тение безопасности любым другим способом, в зависимости от концепции группы.

Эсхатологическая идея может быть любой - катастрофа или кризис, или конец света, описанный в Священных Писаниях различных религиозных традиций, однако события и результаты этих событий, сопровождающие окончание существования жизни на Земле у всех эсхатологических идей похожи. Это полное, либо частичное истребление всего живого, конец света - апокалипсис. Руководствуясь естественной потребностью человека избежать гибели, чаще всего и формируются группы единомышленников, стремящихся к спасению и сохранению своей жизни любой ценой.

В качестве примера эсхатологической идейной группы можно указать - сообщество «пензенских затворников» или «пензенские закопанцы»,[3] которые закопали себя в пещерах Пензенской области в ожидании конца света. Пётр Кузнецов весной 2008 года объявил, что нашёл способ избавиться от зла и грехов и тем самым избежать конца света. Избежать конца света, по его мнению, можно было посредством заточения самих себя в пещеpax. Данный способ был найден посредством собственной трактовки текстов Священного Писания Библии. Петром Кузнецовым была сгенерирована идея избавления, спасения от апокалипсических событий посредством закапывания самих себя в пещерах, предпосылкой же к формированию идеи послужило его мнение о том, что мир нужно спасти от зла.[3] В результате развития его идеи были выработаны, как ему казалось, способы спасения, а, следовательно, и сформулированы были ценности данной эсхатологической идейной группы в виде собственной жизни, морального поведения, абсолютного авторитета Петра Кузнецова. И затем, как способы достижения и сохранения ценностей последовали действия (виды деятельности) - уход к пещерному образу жизни, постничеству и отшельничеству.[7]

По мнению Петра Кузнецова, спастись от всемирной гибели можно было исключительно следующим способом: закопаться под землю в окрестностях молельного дома в селе Никольское Бековского района Пензенской области и пребывать в таком состоянии до получения особых знаков или же до истечения всех угрожающих миру событий. [7] Таким образом, были предприняты действия в соответствии с идеей и ценностями группы. В результате этих действий погибло несколько человек (точно установлена смерть двух пожилых женщин), они скончались от невыносимых условий содержания.[7] В итоге деятельности этой группы общество получило пример появления и возрастания в обществе эсхатологической напряжённости, что является отрицательным опытом в социальной среде.

Как мы видим, из первого примера с пензенскими за- 
творниками, эсхатологическая идейная группа формируется спонтанно и целенаправленно, для нее характерно воздействие идеи отдельно на каждого из индивидов, которую он принимает и фокусирует на ней своё внимание. С течением времени формируется группа, которая впоследствии «централизуется» вокруг идеи. Подобную идейную группу отличает общая идея, которая объединяет людей в идейное сообщество. В идейной группе совместное действие членов группы (вплоть до совместного общинного проживания и ведения хозяйства) продиктовано единой идеей, которая не только объединяет людей вокруг себя, но и является движущей силой, приводящей в действие весь механизм данного сообщества. Не обязательно результаты деятельности будут отрицательными. Например, все христианские и авраамические деноминации ожидают конца света и наступления избавления и спасения людей от смерти. В этом случае, мы получаем положительные влияния от присутствия и воздействия от деятельности идейной группы на общество, поскольку эсхатологическая напряжённость в обществе не возрастает.

Таким образом, идея обретает форму в виде сообщества индивидов, собранных для ее реализации. Это идейное сообщество в процессе реализации идеи создает внутреннюю среду, организационную структуру, разрабатывает способы достижения целей идеи. От своего возникновения до прекращения деятельности идейная группа проходит многоступенчатый путь развития и становления. Этапы возникновения и развития идейной группы можно рассмотреть на примере Миллеритского движения [1; 6, с. 147 - 159] как носителя эсхатологической идеи в момент начала своей деятельности:

1 этап: Предпосылка или повод. В самом начале формирования появляется предпосылка для того, чтобы человек или группа людей проявили беспокойство по отношению своей жизни и здоровью или целостности своего имущества. Происходит формирование объекта опасения. Это могут быть либо события, либо какая-то вещь, которая угрожает большой группе людей, либо всему человечеству. В рассматриваемом случае с Миллеритским движением, это совпадение случайных чисел в случайной временной цепочке, построенной на основании описанного в книге пророка Даниила промежутка времени в 2300 вечеров и утр. [2] Предпосылка должна быть завершённой, иметь целостную форму. Ожидание и факт скорого пришествия Христа не представляет особой опасности для людей в том случае, если оно состоится в далёком будущем, поскольку это уже предсказано в текстах Священного Писания. Актуальность предпосылки приобретается в том случае, если это Второе Пришествие состоится в скорейшем будущем и тому есть доказательства. В качестве доказательств Миллер выбрал свою систему отсчёта - он, руководствуясь собственной логикой, выбрал случайную дату, описанную на страни- цах Священного Писания, которую назвал «временем бесчестия». Следует заметить, что текст книги Даниила написан символичным языком и имеет очень сложную экзегезу, поэтому не составит труда в ходе поверхностного исследования обрести множество смыслов данного текста. В ходе формирования предпосылки или повода ему удалось опереться на имеющие схожий смысл тексты Писания, поэтому предпосылка обрела смысл, оформилась и осмыслялась. Появился предмет, которого люди будут опасаться, а также появилось логически завершённое основание для опасения. Подтверждённый повод для опасения. То, чего следует опасаться, в совокупности с тем, почему этого действительно следует опасаться.

2 этап: Появление идеи. Далее происходит формулирование повода или предпосылки в идею. На данном этапе оформляется способ уберечь себя и своих близких от опасности. Идея как движущая сила для идейной группы - это чётко сформулированные способы для избегания опасений и спасения себя и своих близких от опасности, сформулированной в поводе. Идея группы частично основана на доверии людей друг другу и доверии лидеру. Она содержит в себе также чёткий план или несколько планов по выходу из сложившейся ситуации. Или же это может быть единая цель, достигнув которую группа обретёт желанное спокойствие. Например, У. Миллер предложил людям продать своё имущество, а деньги раздать всем тем, кто не разделяет идею группы. Таким образом, люди полагали обрести прощение и спасение в день Пришествия Христа в строго запланированную дату 1844 года. [1; 6, с. 147 - 159]

3 этап: Формирование ценностей. Идея влияет на появление в группе особых ценностей, того, что будет являться ценным только в рамках данной идейной группы и нигде больше. Это могут быть духовные или материальные ценности. На данном этапе любой факт или вещь в рамках группы производится в ранг ценности в том случае, если она служит или может послужить интересам группы, достижению общих групповых целей или решению общих задач, реализации идеи или идей группы. Миллеритское движение возвело в ценность всё, что может послужить приближению Второго Пришествия Христа. Это в последствии повлияло на формирование религиозной общины Адвентистов Седьмого Дня. Поскольку всё было для людей ценно, они остались верными своим прежним идеалам и сохранили свои прежние ценности практически без существенных изменений.

4 этап: Формирование группы. По мере распространения идеи группы в обществе появляются последователи этой идеи и способы распространения идеи с целью приобретения как можно большего количества последователей. Идейные группы могут быть открытыми, а также могут быть закрытыми для вступления в член- 
ство группы. В закрытых группах количество участников ограничено, и набор ведётся строго до определённого числа членов группы. В случае с Миллеритским движением, привлечение в членство велось по типу классического христианского миссионерства. В результате была сформирована идейная группа количеством в десятки тысяч человек. Происходит разграничение обязанностей, выстраивание иерархии, группа обретает структуру. На данном этапе происходит выявление личных возможностей каждого из членов группы и пригодности его способностей для достижения главной цели и реализации основной идеи.

5 этап: Основная деятельность группы. Процессы, происходящие в группе, можно описать как единая активность и любая возможная деятельность, направленная на достижение единой цели или на спасение от опасности. На этом этапе проявляются любые активности и любые формы деятельности человека как индивида. В Миллиритском движении люди построили большой лагерь из временных палаток, в котором и планировалось встретить Христа. Люди занимаются также и своей повседневной деятельностью, поддерживают свою интеллектуальную деятельность, создают условия для комфортной биологической и социальной активности. Вся деятельность протекает в строгом соответствии идеям и ценностям группы. Главным приоритетом пользуются активности и деятельности, связанные с достижением цели или с выполнением задач группы. Этот этап может занимать любое продолжительное время. От нескольких дней или месяцев, как в Миллеритском движении до многих лет или веков, как, например происходит ожидание Второго Пришествия в Православной Церкви.

6 этап: Этап приближения и наступления эсхатологических событий. Все события, которые происходят в окружающей действительности, которые сопровождают приближение основного центрального события и которые подтверждают ожидания идейной группы относятся к эсхатологическим. Это может быть предвестник катастрофы или предзнаменование чего-либо. Также и наступление какой-то знаковой точной даты будет являться таким событием. На этом этапе могут происходить одно или несколько событий, которые неопровержимо будут свидетельствовать о том, что опасность или наступление основного, центрального, финального события близко. Участники Миллеритского движения приняли в качестве эсхатологических событий моральный упадок и начавшуюся нравственную деградацию общества в это время (середина XIX века) на Американском континенте.

7 этап: Финальное событие или финальное разочарование. Центральное, финальное событие - это и есть эсхатологическое завершение. Конец света, катастрофа или опасность, угроза жизни и здоровью людей, а также и их имуществу, собственно, это то, чего ждали и от чего спасались люди в течение всего времени деятельности идейной группы. На данном этапе предусматривается два варианта развития событий, все происходящие события будут иметь два вектора развития. Либо закономерный финал наступает, все прогнозы и усилия оправдываются, и люди в соответствии со своими идеями группы спасаются от гибели, либо выясняется, что все идеи и ценности, в том числе и основная идея группы ошибочны и от них следует отказаться как от неоправданного опасения. Историки Миллеритского движения так и назовут это время - «время великого разочарования» $[1 ; 6$, с. 147 - 159] после того, как все участники идейной группы данного движения ясно поняли, что конец света не состоялся и все их ожидания и чаяния были напрасными. Затем наступило «время скорби»- утрата былых идей и ценностей, и отсутствие новых.

8 этап: Обретение эсхатона либо корректировка главной идеи, либо отказ от всех идей, прекращение деятельности и расформирование группы. Здесь возможны три вектора развития событий. В том случае, если все эсхатологические события свершились и группа спасена, наступает момент обретения того, что ожидалось после центрального события, по ту сторону эсхатологических ожиданий. Люди пребывают в безопасности или в духовном блаженстве, что является главным благом в религиозном понимании эсхатологической проблемы. Либо, если выяснилось, что все идеи группы были ошибочными, наступает период возвращения людей к своей прежней деятельности после разочарования в прежних идеях и ценностях группы. Это депрессивный и тяжёлый период в жизни бывших членов идейной группы - ресоциализация, возвращение в социум на свои прежние социальные роли. Третий вариант - это реструктуризация и реформация идейной группы, обретение или переустройство главной идеи, выработка новых ценностей или пересмотр прежних, а также определение новых целей и задач группы. Эти процессы могут повлечь за собой переустройство иерархии и внутренней структуры группы. А, возможно, и появление новых идейных групп со схожими целями, задачами, ценностями и идеями. В любом случае, вновь образовавшиеся идейные группы будут заимствовать свои центральные идеи и ценности у уже существовавших, прежних идейных групп. Так, например, в Миллеритском движении после разочарования в прогнозах и ожиданиях произошла реструктуризация и в последствии основные идеи и ценности были заимствованы членами Миллеритского движения выходцами из Евангелистских и методистских общин, которые после «времени разочарования» создали новую общину «Адвентистов Седьмого Дня». Эта община открыто заявляет, что берёт своё начало у движения Уильяма Миллера, которое ожидало Второго Пришествия Христа в 1844 году. [1; 6, с. 147 - 159]

Каждый из этапов развития идейной группы требу- 
ет своего индивидуального подхода к изучению проходящих процессов и происходящих событий как внутри группы, так и за её пределами, в обществе, в котором содержится та или иная идейная группа. Для каждой ступени развития идейной группы необходимо использовать соответствующую методологию. В каждом отдельном типе идейных групп способы и подходы изучения будут разными.

Следует коснуться и социально-философского аспекта феномена идейной группы. Появление идейных групп в обществе является естественным процессом. Граждане имеют право объединяться вокруг определенных идей и их реализовывать в рамках закона. В этом смысле идейная группа - это способ реализации идеи. Совместная деятельность участников идейного сообщества направлена на достижение целей, в соответствии с общей идеей. Идейные группы взаимодействуют с обществом, распространяют свои идеи по мере их продуцирования, проводят мероприятия, разрабатывают методику по достижению своих целей. Они являются носителями альтернативных взглядов отличных от традиционных представлений, принятых в обществе и являются средой для рождения, нетрадиционных или неотрадиционных норм социального поведения. Идейные группы возникают в обществе с необходимостью в качестве альтернативного традиции полюса.

Причин для возникновения нерелигиозной эсхатологической идейной группы много - это появление угрозы уничтожения техногенного или природного характера. Поиск и нахождение способов избежать или уменьшить эту проблему становится идеей эсхатологического идейного сообщества. Готовность или подготовка к действию является главным движущим мотивом для объединения людей в идейные группы. Идея является первопричиной для формирования идейной группы как социального феномена.

Идейная группа есть социальный феномен, состоящий из многих элементов. Людей объединяет в эсхатологические идейные группы не только идея спасения, избавления от угрозы уничтожения, общая система верований, духовные, моральные ценности, но также общие страхи, опасения, трудности. Все эти факторы, составляют элементы, влияющие на формирование идеи и ее смысловое содержание.

В то же время, идейные группы в какой-то степени отделяют себя от общества. Если молодёжные субкультуры присутствуют в городах и «вшиты» в общую структуру цивилизованного общества, то отшельнические поселения или экологические сообщества пытаются полностью изолировать себя от общества.

В качестве примеров не религиозных эсхатологиче- ских идейных групп могут быть названы молодёжные субкультуры, идейные движения, общины экологических поселений, отшельнические группировки. Классическим и самым распространённым примером можно считать неформальное движение «Сюрвевалистов» [8], от англ. «survival» - «выживание», их самоназвание «Выживальщики». Данная идейная группа является ярким примером эсхатологической группы, поскольку их главная идея - спасение от эсхатологических событий посредством укрытия или избегания катастроф при помощи заранее приготовленных способов и методик. Выживальщики принадлежат к антиутопической эсхатологической идее и могут быть условно причислены к маргинальному способу жизни и ведению хозяйства. По их мнению, в скором будущем должна произойти либо катастрофа, либо кризис, либо эпидемия неизлечимого вируса планетарного масштаба (зомби-апокалипсис), в результате чего погибнет основное количество людей на планете, а остатки человечества будут влачить жалкое существование в поисках пропитания и укрытия, объединившись в мелкие группы.

При этом не имеет значения причина возникновения упадка в обществе, в любом случае, прежнего порядка уже нигде не будет и прежнее общество прекратит своё существование. Главная идея группы заключается в том, чтобы накопить как можно большее количество ресурсов, припасов разного назначения и аккумулировать как можно больше средств или способов для выживания в практически непригодных для жизни новых условиях. Основой для формирования такой идеи послужила предпосылка из фильмов ужасов типа «Зомби апокалипсис» (2019 года выпуска), «Рассвет мертвецов» (1978 года выпуска) и многих других, похожих по стилистике и жанру кинокартин упаднического направления. Значения не имеет, какой конкретно сценарий развития эсхатологических событий ожидает мир, но выживальщики как идейная группа ведут подготовку к катастрофе или кризису любого вида, который повлечёт за собой последствия глобального масштаба.

Рассматриваемая эсхатологическая идейная группа в качестве основной идеи принимает страх перед концом света или опасностью планетарного масштаба, которая может привести к апокалипсису. Идея страха может продуцировать исключительно такие же ценности - боязнь, отчуждённость, накопительство и постоянное состояние ужаса в ожидании паники и полного разрушения всего окружающего мира. Эти ценности, приведённые в качестве примера лишь предполагаемые, но этого достаточно для того, чтобы понять, что подобные группы могут вызвать эсхатологическую напряжённость, которой хватит для создания паники в обществе при возникновении подобных предпосылок. В качестве результата деятельности данной группы можно наблюдать повышение эсхатологической напряжённости как 
в рамках идейной группы, так и в обществе в целом.

Идейная группа находится внутри общества и своим присутствием может оказывать на него влияние, привнося в общество свои идеи и ценности. Это влияние может быть конструктивным или деструктивным, положительным или отрицательным. Данные сообщества проходят сложный путь развития от возникновения предпосылки до прекращения существования или трансформации в иное сообщество с идентичными идеями и ценностями. Эсхатологические идейные группы могут создавать ситуацию эсхатологической напряжённости, когда распространяется недостоверная информация о приближении катастрофических событий, призывы к действиям, нарушающим порядок и угрожающие здоровью граждан.
Руководствуясь всем выше сказанным, можно сделать вывод, что эсхатологическая идейная группа - это социальная группа, состоящая из единомышленников, имеющая единую идею как верование или доверие чему-либо или кому-либо, связанная с представлением о неизбежном катастрофическом или любом другом завершении истории человечества. В соответствии с идеями группы формируются ценности или системы ценностей этой группы. Также можно констатировать, что формирование идейной группы происходит по нескольким причинам, таким, как, например, получение каких-то благ, избегание какой-то общей проблемы, достижение единой цели. Обязательным условием для деятельности идейной группы служит, во-первых, наличие одной общей идеи; во-вторых, совершение действий всеми членами группы, приближающих людей к достижению общих целей.

\section{ЛИТЕРАТУРА}

1. David L. Rowe. God's Strange Work: William Miller and the End of the World (Library of Religious Biography) Wm. B. Eerdmans Publishing:, 2008. 249 p.

2. Библия. Синодальное издание. Книга пророка Даниила. Глава 8. стих 14.

3. Круг П., Минин С. Независимая газета. Пензенский андеграунд. 07.04.2008. // Электронный ресурс. Режим доступа на 25.02.2020.: [http://www.ng.ru/ ng_region/2008-04-07/13_underground.html]

4. Лосев А.Ф. Очерки античного символизма и мифологии, Изд. «Мысль», М:, 1993. - 962 с.

5. Ортега-и-Гассет Х., Идеи и верования, ОСR: С. Петров, Перевод В.Г. Резник, 1991.

6. Уайт Е.Г. Великая Борьба. Изд. «Источник жизни». М. ISBN: 5-86847-007-9. 1993.

7. Чаусов. А. Lenta.ru. Псевдоправославие. 7 февраля 2015. // Электронный ресурс. Режим доступа на 25.02.2020.: [https://lenta.ru/articles/2015/02/06/sect/]

8. Электронный ресурс. Режим доступа на 25.02.2020: [https://gnezdoparanoika.ru/podgotovka-k-vijivaniu/133-saiti-vijivanie.html]

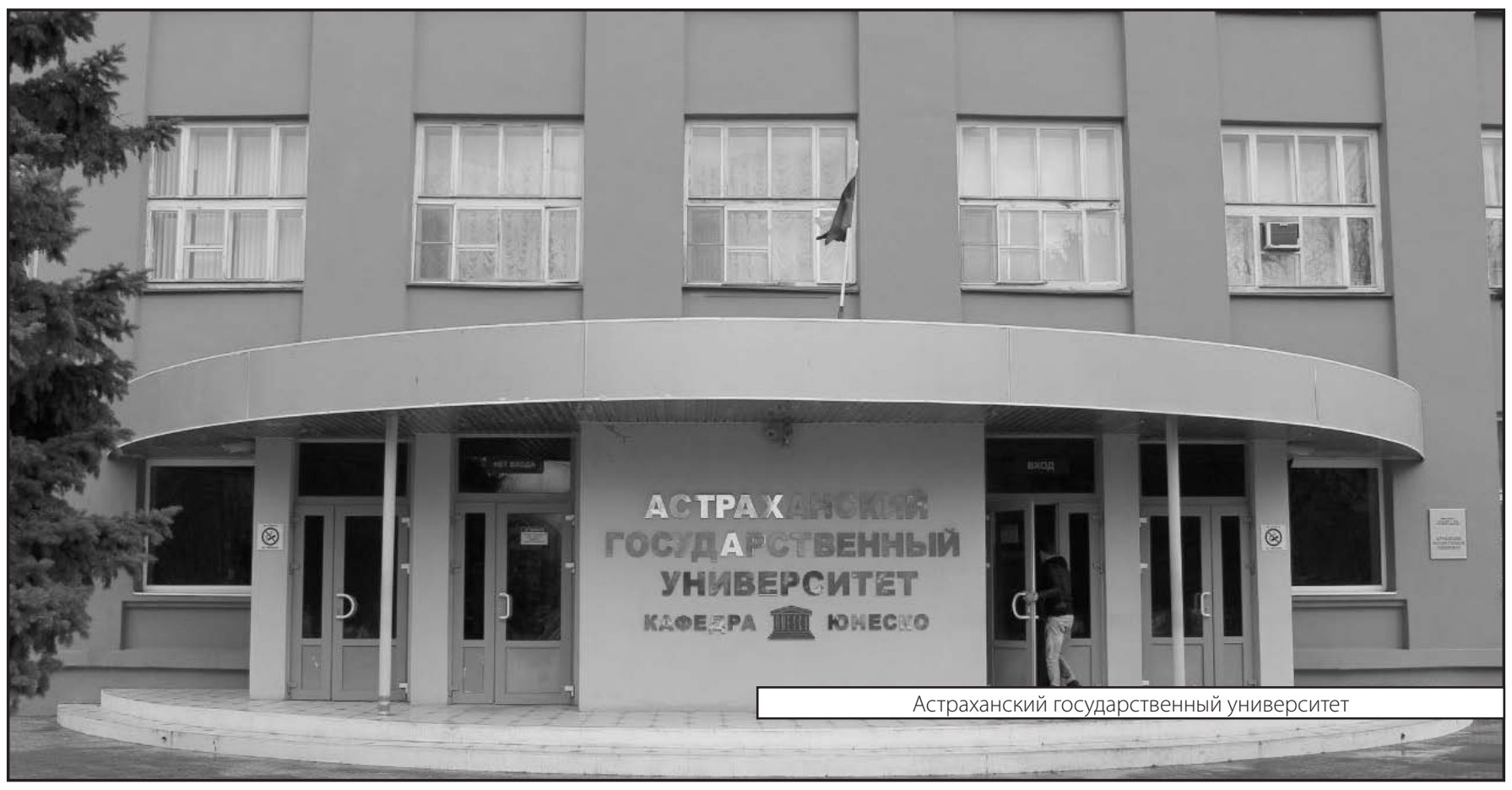

